\title{
On the unique narrative point of view in Tie Ning works-- "3 Stacks"
}

\author{
Zhou mengyan \\ BaiCheng Normal University \\ Baicheng,Jilin,China
}

\begin{abstract}
Owing to the women writers delicate insight, Tie Ning uses "two-way perspective" and "ghost Perspective" novel in her "3 Stacks" to experience, to show the survival status of women, and inherite the legendary motif of ghosts, reaching narrative value-added function.
\end{abstract}

Keywords: Tie Ning novel female narrative perspective uniqueness

\section{INTRODUCTION}

Tie Ning is a famous female writer in the contemporary literary field, she created the novels "Three Heaps (" straw stack "Cotton." Green haystack ") in the mid-eighties to the mid-1990s which showed significance in literature history and were called female literary important works in the development of Tie Ning's representative works of creativity and style transition period. Tie Ning did not simply use the female perspective, but the use of a "two-way perspective" and "Ghosts perspective in order to achieve a unique and comprehensive perspective on life.

\section{A narrative point of view the significance of}

\section{women's writing}

The novel is a narrative art, the first to interpret the narrative text narratology provides a bridge for exploring novel narrative mysteries. In the act of reading, viewing angle is the starting point for the understanding of the text, it is an important factor in determining the readers horizons. Percy
Luke Bo do claimed without any radicalism : the entire complex novel writing skills, the proper choice of perspective are directly related to the success or failure of the novel.

The perspective of the text is complex and varied. Women writing in recent years, is put more attention to the gender perspective. Tie Ning has a unique view in their own writing: "I imagine that it's due to that I have been trying to get rid of female attention when I face the female subject. I am eager to get a two-way perspective or 'third sex' perspective which helps me to more grasp the real female survival situation accurately. "this statement clearly articulate the unique perspective of women in Tie Ning's works: bidirectional Perspective of writing, writing, accurate grasp of the real situation of women survive, then explore the spiritual qualities of human emotions reflect a common human emotion as the ultimate goal. Discarded the objective diaphragm performance female male writers flu, avoiding women writers self-reward inherent in the performance of female narcissism or gender given the natural self-blame mentality of women real soul obscured. She transcended gender objective attitude, and strove to explore the true form of the female life.

\section{The second way}

The narrative perspective explore technique is 
the hottest topic related to bidirectional perspective in the 19th century, and researchers achieve some common views on it. As for the classification of the narrative point of view, it is generally divided into three categories: omniscient perspective; limited viewing angle; and purely objective narrative. In "3 Stacks" which "the straw stack" Cotton "at first glance, the author commonly used omniscient perspective in traditional realism gender as a writing way. For instance, the two (cotton straw and straw stack) out of the "three straws" made gender power possessed the voice of the text naturally .So people called it " the first gender "perspective, while Tie Ning concealed her bidirectional perspective under the omniscient narration.

The three stories in " straw stack "are all completed through a omniscient narrator completion. Every story has two pairs of eyes from female to male. In Yang Qing, Lu Yeming, Shen Xiaofeng's story, we can see that in Shen Xiaofeng's mind world, she acknowledged the original desire of women-the desire for sex . Lu Yeming' s contradiction of both love and dislike, being able to see the women of the male world of the soul standard. Two different pairs of eyes from female and male exist in every story .Through the contradiction of Lu Yeming's both love and dislike, the perfect women standard in men's minds showed. In this standard men have both sex and soul desire for women .In this standard, men not only have physical desire, but also have a spiritual longing. Bi-gender narrative, omniscient narrative interwoven organic integration of psychological processes and plot progress. Certain psychological capacity and frequent two-way perspective changes the whole narrative of the novel.

In the Chi Niang story, we will see Chi Niang's described from an omniscient point of view the life tragedy. Often overlooked story of Tai Chi, and Koike. The mind racing in Tai Chi in the wheat field to see Koike write awareness of female sexual awakening, but also from the the Koike perspective within the focus the way to explore the male sexual awareness. Koike listening uncles and brothers about the story of a woman who grew up in the straw stack. It is in this listen, Koike form a complete image of the female: "That is the Front Street hormone change. Later, he had seen a large Girard's braids, and even do not hesitate to bury her, but he thinks anyway Chi is not the standard of the woman. "[2] Tie Ning here by means of land the wild tomorrow with Koike male perspective to write the standard of women in the male psyche.

"Cotton." Omniscient narrative constantly transform male "country, the old" perspective, the the women "Joe, smelly child's perspective. From this perspective transformation we have a more comprehensive understanding of the fate of women in the dust of history.

Thus, we can see that in the omniscient narrative, Tie Ning actually make full use of the gender perspective, focus on the gender of the two-way cut, omniscient narrative embodies gender meaningful two-way concern. Using the female writers delicate insight, experience the emotional world of women, and the image of women in the male perspective, reflect the state of women's survival, objective and comprehensive understanding of the female.

\section{Ghost Perspective}

For "green haystack, Tie Ning once said:" When I finished writing "Cotton.", I have the idea of "green haystack, the delay to write, because I can not find a most suitable formulation, to tell the main character's story, that I put it off ."Until a month ago, I started and completed a" green haystack, "I thought I found the argument of the story." [3] Tie Ning with six 
years to find suitable for the expression of such a novel, in the narrative in form should more carefully. The analysis of this work that the absurdity of the way is the most unique. Absurd Novel is mainly derived from the the ghosts perspective of select.

The article tells us the story of a man named Feng's youth early in the morning to some other place closing ho, the result of a car accident death. His soul aboard pulling coal cars to yellow rice store, then went to a nightclub. Through liquor power the magistrate and Director and other officials to the naked state brought dance, and then returned home in the green haystack, until Green haystack was burned, and only out of their wits. The representation of the whole story with the ghost of von early in the morning to complete. Perspective of this ghost, on the one hand, to form a narrative contract between the narrator and the reader, on the other hand, reached the narrative function of the value-added.

In the first person narrative angle, the protagonist is given ghost identity of an intent to expand the perspective of the reader, it is a great temptation. When the novel in the first person, the reader can not acquire omniscient perspective, but may produce strong hero echoes feelings. When the first-person narrator is a ghost, the ghost of a special existence by time and space constraints, which allows the reader in generating strong ECOWAS feelings, but also have an omniscient perspective. Most important thing is "green haystack" a ghost as a narrator, a narrative contract between the narrator and the reader, this contract has two: First, the description of the authenticity of the content; One narrative The objectivity of the content.

The authenticity of the narrative content when using this ghost perspective, people its narrative content to form a sense of trust. Ghost as a narrator, and his presence is bound by time and space, he can be described life can not be heard by others, a great broaden the narrative content. The most important is when the ghost as a focus by him both as a person exists in the world of the novel, but not focused object perception. The focus objects completely relieved of any society, history and culture of the public eye, watched, the light and spacious realm of the body and mind in a very free and relaxed self Benxiang. This ensures that the reading will be a greater degree of trust ghost Perspective narrative content to generate a strong sense of realism.

Objectivity of the narrative from the relationship between the narrator and the characters. The ghost writing perspective, the narrator with the characters has a dual relationship: the one hand, he maintained relations with the figures, on the other hand does not have to intervene in their lives. Narrator able to observe life and comments on life both insider and outsider dual identity. This dual identity both to avoid the narrator by the idea first or tied, but also avoid the restrictions by the relationship between the characters. So that the reader believe that, as described by the narrator is standing objective stance expressed.

Ghost writing, its tradition of Chinese literature. Ming Dynasty Feng Meng Yu Shiming Yan, a story of "Yangsi temperature the Yanshan case the enemy". Yangsi temperature in the Lantern Festival occasional sworn brother of the late wife Zheng Italian mother. Yangsi temperature to know its people deceased, asked and her's is a man is a ghost, Zheng intended Niang A: Pacific of the World, people ghost phase points, today's World, people ghost phase miscellaneous. "[4] Zheng Italian mother's the story can be seen as an important motif in the legendary classical Chinese ghosts: Health when the troubled times, the social order of the heavens and the earth at a loss without memory, various go beyond reasonable force looked spread of life and death staggered 
the people ghost with passers. Scholars David Wang believes that the value of one of the most important of the writing of this ghostly legend satirical. From David Wang's point of view, back to the narrative content of the "green haystack. The novel is based on the reform and opening up, China's rural background for the novel, write, and since many of China's reform and opening up some of the real problem: official corruption, moral decline. These practical problems are both described by a ghost, ghosts and involved. Throughout the narrative process, the writer did not raise any criticism that concept, but has critical kernel. With the ghost of the legendary motif, and expression of reform in the context of some of the evils of ruthless sarcasm. When the narrator as a character with real life characters "Ghost-phase hybrid" undoubtedly played a ghostly legend of the tenor, relentless scathing mockery of real human feelings.

This ghost perspective is another value-added in the narrative content is to convey a "return to consciousness.

Purpose of textual research on the etymology, cross-training "ghost" in ancient and "return" can not readily "ELEGANCE" said, "ghost words normalized also." [5] Here "normalized" in the Book of Rites: "all creatures die, and death shall be upon the earth: this is called the ghost." Zuo Zhao Gong seven ": the ghost somewhere to go, not $\mathrm{Li} \mathrm{I}$ as normalized also." from this explanation As can be seen, the "normalization" with the usual sense of the home is not the same, more is to find a place to regression. As Christian said, "dust to dust, soil into the earth." Means to find the dwelling of the soul, to convey a return to their homes consciousness. In the "green haystack", the hero's death in a foreign land, the ghost of the existence of the state is a foreign land, and novel clues a Homecoming clues: Steeped yellow shop - School - Hotel - Green haystack. Meanwhile, the fusion of an important growth experience of childhood, youth, youth, completed mentally regression.

\section{CONCLUSIONS}

Tie Ning chose to use "two-way viewing angle in "3 Stacks" avoiding narrow bigotry of writing limited by the angle of women or men broadened the horizons of the people to express life. On the other hand, the use of "ghost Perspective $t$ strengthened the readers" narrative content realism and objectivity recognition and inherited the legendary motif of ghosts, making the narrative function of the value-added.

\section{References:}

[1]. Zhu Hongmin. Narratology of Tie Ning "vision three Duo" [J]. Journal of Hebei Normal University (PHILOSOPHY AND SOCIAL SCIENCE EDITION). 2007 (02)

[2]. Yan Hong. On Tie Ning "three Duo" inheritance of five four female literature and beyond [J]. Journal of Langfang Teacher's College. 2003 (03)

[3]. Li Lin. A unique way of Tie Ning female [J]. Journal of Capital Normal University (SOCIAL SCIENCE EDITION). 2000 (03) 